\title{
Towards industrially-feasible delignification and pitch removal by treating paper pulp with Myceliophthora thermophila laccase and a phenolic mediator
}

\author{
Esteban D. Babot ${ }^{\mathrm{a}}$, Alejandro Rico ${ }^{\mathrm{a}}$, Jorge Rencoret ${ }^{\mathrm{a}}$, Lisbeth Kalum ${ }^{\mathrm{b}}$, Henrik Lund ${ }^{\mathrm{b}}$, \\ Javier Romero ${ }^{c}$, José C. del Río ${ }^{a}$, Ángel T. Martínez ${ }^{d}$, Ana Gutiérrez ${ }^{\mathrm{a}, *}$ \\ a Instituto de Recursos Naturales y Agrobiología de Sevilla, CSIC, P.O. Box 1052, E-41080 Seville, Spain \\ ${ }^{\mathrm{b}}$ Novozymes A/S, Krogshoejvej 36, DK-2880 Bagsvaerd, Denmark \\ ${ }^{\mathrm{c}}$ ENCE, Marisma de Lourizán s/n, P.O. Box 157, E-36080 Pontevedra, Spain \\ ${ }^{\mathrm{d}}$ Centro de Investigaciones Biológicas, CSIC, Ramiro de Maeztu 9, E-28040 Madrid, Spain
}

\section{A R T I C L E I N F O}

\section{Article history:}

Received 15 February 2011

Received in revised form 30 March 2011

Accepted 30 March 2011

Available online 2 April 2011

\section{Keywords:}

Laccase

Methyl syringate

Pitch deposits

Pulp bleaching

Syringaldehyde

\begin{abstract}
A B S T R A C T
The ability of two natural phenols to act as mediators of the recombinant Myceliophthora thermophila laccase (MtL) in eucalypt-pulp delignification was investigated. After alkaline peroxide extraction, the properties of the enzymatically-treated pulps improved with respect to the control. The pulp brightness increased (3.1 points) after the enzymatic treatment with MtL alone, but the highest improvements were obtained after the MtL treatment using syringaldehyde (4.7 points) and especially methyl syringate (8.3 points) as mediators. Likewise, a decrease in kappa number up to 2.7 points was obtained after the MtLmethyl syringate treatment, followed by decreases of 1.4 and 0.9 points after the treatments with MtLsyringaldehyde and MtL alone, respectively. On the other hand, removal of the main lipophilic extractives present in eucalypt pulp was observed after the above laccase-mediator treatments. Finally, the doses of both MtL and methyl syringate were reduced, and results compatible with industrial implementation were obtained.
\end{abstract}

(c) 2011 Elsevier Ltd. All rights reserved.

\section{Introduction}

The paper pulp industry is facing an increasing pressure to replace the conventional pulp bleaching techniques, using chlorine-based chemicals, with more environmentally-benign ones. Enzymes offer an environmentally benign and efficient alternative to chemical reagents in many industrial applications, including pulp and paper manufacture (Kenealy and Jeffries, 2003). Lipases (pitch control) and xylanases (bleaching) were introduced in the mill several years ago (Gutiérrez et al., 2001a; Bajpai et al., 2006), yet lignin-degrading oxidoreductases offer additional benefits compared to xylanases for pulp bleaching because they act directly on lignin. Likewise, oxidoreductases also have a high potential for pitch control because they act over a wide range of lipophilic compounds by a recently described oxidative mechanism (Gutiérrez et al., 2009).

Laccases (EC 1.10.3.2) are multicopper oxidases that use molecular oxygen as the final electron acceptor and have been object of high interest for the development of environmentallybenign technologies (Mayer and Staples, 2002). The direct action

\footnotetext{
* Corresponding author. Tel.: +34 954624711; fax: +34 954624002.

E-mail address: anagu@irnase.csic.es (A. Gutiérrez).
}

of laccases on lignin is in principle restricted to the phenolic units that only represent a small percentage of the total polymer, a fact that limits its biotechnological application for paper pulp delignification. However, the interest on laccases as industrial biocatalysts steadily increased after discovering the effect on laccase activity of some synthetic compounds, including 2,2'-azinobis(3-ethylbenzothiazoline-6-sulphonic acid) (ABTS) (Bourbonnais and Paice, 1990) and 1-hydroxybenzotriazole (HBT) (Call, 1994) acting as electron carriers between the enzyme and the final substrate. In this way, the action of laccase is expanded to non-phenolic substrates, which are oxidised by the mediator radical, increasing the potential of the enzyme in degradation of lignin and other aromatic compounds. Since then, a variety of studies have confirmed the potential of the so-called laccase-mediator system for bleaching different pulp types (Bourbonnais and Paice, 1996; Poppius-Levlin et al., 1999; Camarero et al., 2004; Moldes and Vidal, 2008; Fillat and Roncero, 2010). On the other hand, the modification of some lipophilic extractives by laccases has been suggested (Zhang et al., 2005), and recently it was reported the high efficiency of the laccasemediator system for the removal of lipophilic extractives regardless the pulping process and the raw material used (Gutiérrez et al., 2006a,b; Molina et al., 2008; Valls et al., 2009) and a patent was filed on this application (Gutiérrez et al., 2006c). 
However, the cost, safety and environmental profile of some of the synthetic mediators included in most of the above studies make it difficult to implement laccase-mediator systems in pulp bleaching at industrial scale. Recently, several lignin-related natural phenols, which form stable radicals, have been investigated as laccase mediators for pulp bleaching (Camarero et al., 2007; Fillat et al., 2010) and removal of lipophilic extractives from pulp (Gutiérrez et al., 2007). The present paper provides the first evidence of the feasibility of using a commercial laccase, and a cheap natural phenol with a suitable redox potential (Kulys et al., 2002) as mediator, for removing lignin and lipids from paper pulp. The enzyme used is the thermostable laccase from the ascomycete Myceliophthora thermophila, which has been cloned, expressed in Aspergillus oryzae, biochemically characterized, and commercialized (Xu et al. 1996; Berka et al., 1997). The results presented make the laccasemediator treatment economically feasible from an industrial point of view.

\section{Methods}

\subsection{Pulp}

Eucalyptus globulus unbleached kraft pulp, with a kappa number of 15.5 ( 2.3\% lignin content), brightness of 38.5\% ISO, and intrinsic viscosity of $1187 \mathrm{~mL} \mathrm{~g}^{-1}$ was obtained from the ENCE mill in Pontevedra (Spain) and used in enzyme treatment and control experiments.

\subsection{Fungal laccase and mediators}

A commercial fungal laccase from the ascomycete $M$. thermophila, provided by Novozymes (Bagsvaerd, Denmark) was used in this study. Laccase activity was measured as initial velocity during oxidation of $5 \mathrm{mM}$ ABTS from Roche to its cation radical $\left(\varepsilon_{436}\right.$ $\left.29,300 \mathrm{M}^{-1} \mathrm{~cm}^{-1}\right)$ in $0.1 \mathrm{M}$ sodium acetate ( $\left.\mathrm{pH} \mathrm{5}\right)$ at $24^{\circ} \mathrm{C}$. The laccase activity of the enzyme preparation was $945 \mathrm{U} / \mathrm{ml}$. One activity unit (U) was defined as the amount of enzyme transforming $1 \mu \mathrm{mol}$ of ABTS per min. A fungal laccase preparation $(45 \mathrm{U} / \mathrm{ml})$ obtained from a laccase-hyperproducing strain of the basidiomycete Pycnoporus cinnabarinus that was provided by Beldem (Andenne, Belgium) was also used for comparative studies.

Syringaldehyde (4-hydroxy-3,5-dimethoxybenzaldehyde; Cat: S760-2, Lot.: S16872-326) from Sigma-Aldrich (Steinheim, Germany) and methyl syringate (methyl 4-hydroxy-3,5-dimethoxybenzoate; Cat.: A18054/L05417, Lot.: 10110113) from Alfa Aesar (Karlsruhe, Germany) were assayed as mediators.

\subsection{Laccase-mediator treatments of eucalypt pulp}

First, pulp treatments with $M$. thermophila laccase (MtL)-mediator were carried out in duplicate using $10 \mathrm{~g}$ (dry weight) of pulp at $3 \%$ consistency (w:w) in $50 \mathrm{mM}$ sodium dihydrogen phosphate buffer ( $\mathrm{pH}$ 6.5). Laccase loading was $20 \mathrm{U} \mathrm{g}^{-1}$ pulp and concentration of mediators (syringaldehyde and methyl syringate) in the reaction was kept at $6.75 \mathrm{mM}$. The treatments were carried out in $500 \mathrm{~mL}$ flasks with $\mathrm{O}_{2}$ bubbling, placed in a thermostatic shaker at $170 \mathrm{rev} \mathrm{min}{ }^{-1}$ and $50^{\circ} \mathrm{C}$, for $12 \mathrm{~h}$. Finally, some enzymatic treatments (with MtL) were performed in $200 \mathrm{~mL}$ bioreactors (Labomat, Mathis) under conditions more similar to those of industrial application (including $10 \%$ pulp consistency and 4 bar oxygen pressure).

Pulp treatments were repeated in the presence of Tween 20 (Cat.: TW00200250, Lot.: 10926401) or Tween 80 (Cat.: TW00800250, Lot.: 10628801) from Scharlau (0.05\% w:v) and with lower doses of laccase (from $20 \mathrm{U} \mathrm{g}^{-1}$ to $1 \mathrm{U} \mathrm{g}^{-1}$ pulp) and mediator (from $6.75 \mathrm{mM}$ to $0.6 \mathrm{mM}$ ).
In a subsequent step, pulps at 5\% consistency (w:w) were submitted to an alkaline peroxide extraction (Ep) using 3\% (w:w) $\mathrm{H}_{2} \mathrm{O}_{2}$ and $1.5 \%$ (w:w) $\mathrm{NaOH}$, both referred to pulp dry weight, at $90^{\circ} \mathrm{C}$ for $2 \mathrm{~h}$. Controls including laccase without mediator were also performed.

Pulp treatments with $P$. cinnabarinus laccase were performed as described above for $M$. thermophila ones, but using $50 \mathrm{mM}$ sodium tartrate ( $\mathrm{pH} 4)$ as a buffer.

\subsection{Pulp lipid extraction and chromatographic analysis}

Treated pulps and controls were air dried and samples were Soxhlet-extracted with acetone for $8 \mathrm{~h}$ (Gutiérrez et al., 2001b). All extracts were evaporated to dryness and redissolved in chloroform for analysis of the lipophilic fraction by gas chromatography (GC) and gas chromatography-mass spectrometry (GC-MS).

The GC analyses of lipids were performed in an Agilent $6890 \mathrm{~N}$ Network GC system using a short fused-silica DB-5HT capillary column $(5 \mathrm{~m} \times 0.25 \mathrm{~mm}$ internal diameter, $0.1 \mu \mathrm{m}$ film thickness $)$ from J\&W Scientific, enabling simultaneous elution of the different lipid classes (Gutiérrez et al., 1998). The temperature program started at $100{ }^{\circ} \mathrm{C}$ with $1 \mathrm{~min}$ hold, then raised to $350^{\circ} \mathrm{C}$ at $15^{\circ} \mathrm{C} \mathrm{min}-1$, and held for $3 \mathrm{~min}$. The injector and flame-ionization detector (FID) temperatures were set at $300^{\circ} \mathrm{C}$ and $350{ }^{\circ} \mathrm{C}$, respectively. Helium ( $\left.5 \mathrm{~mL} \mathrm{~min}^{-1}\right)$ was used as carrier gas, and the injection was performed in splitless mode. Peaks were quantified by area.

The GC-MS analyses were performed with a Varian 3800 chromatograph coupled to an ion-trap detector (Varian 4000) using a medium-length $(12 \mathrm{~m})$ capillary column of the same characteristics described above for GC using FID. The oven was heated from $120^{\circ} \mathrm{C}(1 \mathrm{~min})$ to $380^{\circ} \mathrm{C}$ at $10^{\circ} \mathrm{C} \mathrm{min}^{-1}$, and held for $5 \mathrm{~min}$. The transfer line was kept at $300{ }^{\circ} \mathrm{C}$, the injector was programmed from $120^{\circ} \mathrm{C}(0.1 \mathrm{~min})$ to $380^{\circ} \mathrm{C}$ at $200^{\circ} \mathrm{C} \mathrm{min}-1$ and held until the end of the analysis, and helium was used as carrier gas at a rate of $2 \mathrm{~mL} \mathrm{~min}{ }^{-1}$. Compounds were identified by mass fragmentography, and by comparing their mass spectra with those of the Wiley and NIST libraries, and standards.

\subsection{Pyrolysis-GC-MS analysis of pulp lignin}

Pyrolysis of pulps (approximately $1 \mathrm{mg}$ ) after Soxhlet extraction with acetone, was performed with a 2020 micro-furnace pyrolyzer (Frontier Laboratories Ltd.) connected to an Agilent 6890 GC-MS system equipped with a DB-5MS (Agilent J\&W) fused-silica capillary column ( $30 \mathrm{~m} \times 0.25 \mathrm{~mm}$ i.d., $0.25 \mu \mathrm{m}$ film thickness $)$ and an Agilent 5973 mass selective detector (EI at $70 \mathrm{eV}$ ). The pyrolysis was performed at $500{ }^{\circ} \mathrm{C}$. The oven temperature was programmed from $40^{\circ} \mathrm{C}(1 \mathrm{~min})$ to $300^{\circ} \mathrm{C}$ at $6^{\circ} \mathrm{C} \mathrm{min}^{-1}(10 \mathrm{~min})$. Helium was the carrier gas $\left(1 \mathrm{~mL} \mathrm{~min}^{-1}\right)$. The compounds were identified by comparing their mass spectra with those of the Wiley and NIST libraries.

For pulp lignin analysis in terms of its p-hydroxyphenyl: guaiacyl:syringyl (H:G:S) composition, single-ion pyrolysis-GCms (Py-GC-MS) traces were obtained using the molecular ions of the following selected markers (del Río et al., 2001): $\mathrm{m} / z$ 108 (4methylphenol), 122 (4-ethylphenol), 120 (4-vinylphenol) and 134 (4-t-propenylphenol) for H-lignin units; $\mathrm{m} / \mathrm{z} 138$ (4-methylguaiacol), 152 (4-ethylguaiacol), 150 (4-vinylguaiacol) and 164 (4-t-propenylguaiacol) for G-lignin units; and $m / z 168$ (4-methylsyringol), 182 (4-ethylsyringol), 180 (4-vinylsyringol), and 194 (4-t-propenylsyringol) for S-lignin units. Phenol, guaiacol and syringol were not selected as lignin markers, to prevent interferences due to eventual formation of syringol from residual amounts of the S-type mediators used. 


\subsection{Papermaking evaluation of eucalypt pulps}

Pulp brightness, kappa number (before and after acetone extraction, as described in Section 2.4) and intrinsic viscosity were analyzed following ISO 3688:1999, ISO 302:1981 and ISO 5351/ 1:1981 standard methods, respectively (International Organization for Standardization Documentation and Information (ISO), 2003). Data from replicates were averaged. In all cases the standard deviations were below $2 \%$ of the mean values.

\section{Results and discussion}

In this paper, the ability of recombinant MtL to delignify eucalypt kraft pulp, and simultaneously remove lipophilic extractives causing pitch deposits, in the presence of two simple S-type phenols of plant origin (syringaldehyde and methyl syringate) was tested. The commercially available MtL retains activity through a wide $\mathrm{pH}$ range (from $\mathrm{pH} 4$ to $\mathrm{pH}$ 9) and has higher thermostability (being active up to $70^{\circ} \mathrm{C}$ ) than the different basidiomycete laccases investigated for biotechnological application (Xu et al., 1996). More importantly, MtL can be heterologously expressed in industrial hosts (such as Aspergillus species) with high yields (Berka et al., 1999), compared with the basidiomycete laccases whose heterologous expression results in low yields currently limiting their largescale commercialization in pulp bleaching.

\subsection{Pulp delignification with MtL and S-type mediators}

Unbleached eucalypt kraft pulp was treated with MtL in the presence and absence of syringaldehyde and methyl syringate, and subsequently extracted with alkaline peroxide. The delignification degree was evaluated before and after the alkaline peroxide extraction, by determining the kappa number (an estimation of lignin content in pulp) and the ISO brightness. Intrinsic viscosity (an estimation of cellulose integrity) was also determined. The results obtained are shown in Table 1, compared with the control pulp.

The positive effects of the enzymatic treatments on pulp properties, especially on brightness, were only evidenced after the alkaline extraction, revealing the need of an alkaline peroxide stage after the treatment with laccase and natural mediators. In the absence of this extraction, the pulp brightness decreased with the enzymatic treatment. Likewise, the kappa number only decreased 0.4 and 1.1 points with the MtL alone and in the presence of methyl syringate, respectively, and increased 1.2 points with the MtL-syringaldehyde treatment (due to partial retention of the mediator on the non-extracted pulp). After the peroxide extraction, the properties of the treated pulps improved with respect to the control. The brightness of eucalypt pulp increased up to 3.1, 4.7 and 8.3 points after the treatments with MtL alone, MtL-syringaldehyde, and MtL-methyl syringate, respectively. On the other hand, a decrease in kappa number up to 2.7 points was obtained after the MtL-methyl syringate treatment followed by a decrease of 1.4 points in the MtL-syringaldehyde treatment and by 0.9 points decrease in the treatment with MtL alone. The increased delignification (up to $25 \%$ ) and brightness (up to 15\%) obtained using methyl syringate as mediator are very promising results since they provide the first evidence on pulp properties improvement using a commercial laccase and a cost-effective natural mediator.

\subsection{Comparison with other laccases and mediators}

For comparative purposes, the (non-commercial) laccase from the basidiomycete Pycnoporus cinnabarinus (PcL) was also applied to eucalypt pulp in the presence of syringaldehyde and methyl syringate as mediators (data not shown). In spite of PcL being a high-redox potential laccase, less reactivity was shown towards lignin (compared with MtL) since worse results in terms of brightness increase (only 0.5 points) and kappa decrease (only 0.1 points) were obtained in the treatments with laccase alone. In the PCL treatments carried out in the presence of syringaldehyde and methyl syringate, similar increases in brightness (about 5 points) and decreases in kappa number (about 1 point) were obtained with both mediators. These results are inferior to those described above using the MtL and methyl syringate as mediator.

The above improvements of eucalypt pulp brightness are lower than reported using the synthetic mediator HBT in combination with high redox-potential laccases from basidiomycetes (Camarero et al., 2007), although the latter treatment has not been industrially implemented due to the high cost and environmental issues associated to this and other synthetic mediators. However, the low redox-potential laccase from the ascomycete $M$. thermophila can be heterologously expressed in A. oryzae, in contrast to the high redox-potential basidiomycete laccases. Therefore, MtL has the advantage of being a commercially-available cheap laccase, which will enable the up-scaling of the enzymatic treatment of pulp. Although low redox-potential laccases cannot oxidize mediators such as HBT (Ibarra et al., 2006), this is not a problem here since the mediators used (syringaldehyde and methyl syringate) are phenolic mediators of low redox-potential. These phenolic mediators can be easily obtained from natural sources and are also present in eucalypt pulping liquor (Gutiérrez et al., 2007). In addition, the decrease in pulp viscosity reported here (5\%) is lower than that produced using HBT (18\%) (Camarero et al., 2007).

\subsection{Enzymatic modification of pulp lignin as shown by analytical pyrolysis}

With the aim of investigating how the enzymatic treatment affects the composition of residual lignin, the lignin in the enzymatically-treated pulps was analyzed by pyrolysis coupled to GC-MS. Py-GC-MS allows for in situ analysis of lignin by chromatographic separation and mass-spectrometric identification of the compounds released after the pyrolytic breakdown of whole pulp. Unfortunately, the lignin content in chemical pulps is often too low for direct detection of these breakdown products. However, their relative abundances can be analyzed in single-ion chromatographic traces

Table 1

Pulp papermaking properties (kappa number, brightness, and viscosity) and lignin S/G molar ratio (from selected Py-GC-MS markers, see SD Fig. S1) of eucalypt pulp treated with M. thermophila laccase (MtL) in the absence and presence of syringaldehyde (SA) or methyl syringate (MS), and control without enzyme, before and after an alkaline peroxide extraction (Ep).

\begin{tabular}{|c|c|c|c|c|c|c|c|c|}
\hline & \multicolumn{2}{|l|}{ Control } & \multicolumn{2}{|l|}{ MtL } & \multicolumn{2}{|l|}{ MtL-SA } & \multicolumn{2}{|l|}{ MtL-MS } \\
\hline & Before Ep & After Ep & Before Ep & After Ep & Before Ep & After Ep & Before Ep & After Ep \\
\hline Kappa number & 13.3 & 10.7 & 12.9 & 9.8 & 14.5 & 9.3 & 12.2 & 8.0 \\
\hline Brightness (\% ISO) & 43.5 & 57.0 & 41.5 & 60.1 & 35.6 & 61.7 & 36.5 & 65.3 \\
\hline Intrinsic viscosity $\left(\mathrm{mL} \mathrm{g}^{-1}\right)$ & 1230 & 1030 & 1240 & 1020 & 1220 & 972 & 1240 & 978 \\
\hline $\mathrm{S} / \mathrm{G}$ ratio & 1.45 & 0.92 & 1.10 & 0.61 & 1.19 & 0.55 & 0.73 & 0.26 \\
\hline
\end{tabular}


corresponding to selected marker compounds, as described by del Río et al. (2001).

Although the Py-GC-MS analyses were performed after pulp extraction with acetone (and kappa numbers only slightly varied before and after the extraction) the presence of residual syringaldehyde and methyl syringate was detected in chromatographic traces corresponding to their molecular ions $(\mathrm{m} / z 182$ and 212 respectively). With the aim of preventing an eventual interference of these compounds, syringol was excluded from the selected markers used to analyze pulp residual lignin, together with phenol and guaiacol (see Supplementary Data, SD, Fig. S1). From the traces obtained (that did not show H-type lignin markers), the relative lignin composition in the enzymatically-treated eucalypt pulps and controls were calculated, and shown in Table 1 as S/G molar ratios. A slight decrease in the $S / G$ ratio was already observed after the enzymatic treatment with MtL alone, which was the largest after MtL treatment in the presence of methyl syringate followed by the alkaline peroxide stage, indicating a preferential removal of lignin S-units by this laccase-mediator system. This result is in agreement with a more linear structure of $\mathrm{S}$ lignin with a predominance of $\beta-O-4$ ' inter-unit linkages (Ibarra et al., 2007), while G lignin is more condensed (branched) due to additional linkages involving the $\mathrm{C} 5$ position at the benzenic ring (which is blocked by a second methoxy group in S-units) making it more resistant towards degradation.

\subsection{Pitch removal with MtL and S-type mediators}

The removal of lipophilic extractives by eucalypt pulp treatments with MtL and syringadehyde and methyl syringate as mediators, was evaluated before and after the alkaline peroxide extraction by GC and GC-MS analyzes. The results obtained are shown in Table 2. The main lipophilic compounds present in eucalypt pulp (see SD, Fig. S2A) included sterols (predominantly sitosterol) in free (c) and esterified (j) form. Minor amounts of sterol glycosides ( $\mathrm{g}$ ) were also present. The detailed composition of lipophilic extractives from eucalypt pulp has been published elsewhere (Gutiérrez and del Río, 2001b). These compounds have been shown to be the main responsible for pitch problems during manufacturing of eucalypt pulp (Gutiérrez et al., 2009).

It was observed (Table 2) that the enzymatic treatment (without the subsequent alkaline peroxide extraction) using laccase alone was able to partially remove the free sterols (about $25 \%$ ) and sterol esters (about 41\%). When the laccase treatment was performed in the presence of syringaldehyde, a decrease of free sterols (up to 73\%), sterol glycosides (up to 91\%) and sterol ester (about $89 \%$ ) contents, was produced (see SD, Fig. S2B). A similar removal of sterol esters (up to 92\%) seems to be attained in the laccase treatments using methyl syringate as mediator (see SD, Fig. S2C), whereas a lower decrease of free sterols (up to $48 \%$ ) was observed. A decrease on the sterol glycoside content was not observed with the latter mediator. Similar values of lipophilic extractives removal were obtained in the enzymatic treatments followed by the alkaline peroxide extraction (Table 2 ).
Several oxidation products of steroids were observed in the pulps as a result of enzymatic treatment that were especially evident in the treatments with syringaldehyde (see SD, Fig. S2B). Some of them were already present in the control although in low amounts. Among them, the main compound identified was 7-ketositosterol (f) followed by 7 $\beta$-hydroxysitosterol (d) with only traces of $7 \alpha$-hydroxysitosterol. Other products found in the treated samples were triols, such as sitostanetriol (e). By observing the oxysterol pattern, it could be inferred that oxidation would start with the abstraction of a reactive allylic hydrogen at $C_{7}$ followed by oxygen attack to form the peroxy radical. Hydrogen addition to this radical gives the 7-hydroperoxide, whose degradation forms the stable $7 \alpha$ - and $7 \beta$-hydroxysitosterol and 7-ketositosterol (Johnsson, 2004). On the other hand, sitostanetriol may be formed after hydration of the epoxides, although the latter compounds were not detected in the pulp samples. Further oxidation of the above oxidation products leads to dehydration and subsequent abstractions of the hydroxy group on $\mathrm{C}_{3}$, which generates conjugated dienes and trienes such as stigmasta-3,5-diene (b) and stigmasta-3,5,7-triene (a), which increased in the enzymaticallytreated pulps. Other oxidized derivatives, which appeared with the enzymatic treatment, included 7-ketositosteryl 3 $\beta$-D-glucopyranoside (i) formed by the oxidation of sitosteryl 3 $\beta$-D-glucopyranoside and the oxidation products of sterol esters tentatively assigned to sitosterol ester core aldehyde (n).

\subsection{Effect of Tween (20 and 80) on enzymatic delignification and pitch removal}

The above results on pulp delignification and pitch removal were obtained in laccase-mediator treatments without addition of any surfactant. Since most of the published studies on laccasemediator treatment of paper pulps have been performed in the presence of Tween 80 (Moldes and Vidal, 2008; Fillat et al., 2010), the effect of surfactant addition was also studied here. Taking into account that Tween 80 (due to its content of unsaturated fatty acids) can promote peroxidation reactions (Jensen et al., 1996 ) in addition to its surfactant effect, enzymatic treatments in the presence of Tween 20 (which contains only saturated fatty acids) were also carried out. Table 3 shows the effect of the addition of Tween 20 and Tween 80 to the pulp treatments with laccase alone, as well as in the presence of syringaldehyde or methyl syringate, on the pulp properties. Concerning kappa number, no differences could be observed among the enzymatic treatments performed in the absence and presence of Tween. In contrast, lower brightness values were obtained, especially in the presence of Tween 80 . Only the viscosity values show an improvement in the treatment with Tween 80 .

The effect of adding Tween on the enzymatic removal of lipophilic extractives from eucalypt pulp was also evaluated. Generally, the removal of lipophilic extractives (data not shown) did not improve with respect to those without addition of Tween (Table 2). Only the removal of sterol glycosides was increased by the addition of Tween 20 and Tween 80 in the treatments with

Table 2

Removal (percentage of reduction) of the main lipophilic extractives (steroids) from eucalypt pulp after treatment with $M$. thermophila laccase (MtL) in the absence and presence of syringaldehyde (SA) or methyl syringate (MS) before and after an alkaline peroxide extraction (Ep).

\begin{tabular}{|c|c|c|c|c|c|c|}
\hline & \multicolumn{2}{|l|}{ MtL } & \multicolumn{2}{|l|}{ MtL-SA } & \multicolumn{2}{|l|}{ MtL-MS } \\
\hline & Before Ep & After Ep & Before Ep & After Ep & Before Ep & After Ep \\
\hline Free sterols & 25 & 21 & 73 & 69 & 48 & 40 \\
\hline Sterol glycosides & 0 & 7 & 91 & 86 & 24 & 24 \\
\hline Sterol esters & 41 & 41 & 89 & 82 & 92 & 80 \\
\hline
\end{tabular}


Table 3

Effect of the addition of Tween 20 (T20) or Tween 80 (T80) on the modification of eucalypt pulp properties (kappa number, ISO brightness and intrinsic viscosity) by M. thermophila laccase (MtL) treatment in the absence and presence of syringaldehyde (SA) or methyl syringate (MS), and control without Tween (Con), followed by an alkaline peroxide stage.

\begin{tabular}{|c|c|c|c|c|c|c|c|c|c|}
\hline & \multicolumn{3}{|l|}{ MtL } & \multicolumn{3}{|c|}{ MtL-SA } & \multicolumn{3}{|c|}{ MtL-MS } \\
\hline & Con & $\mathrm{T} 20$ & $\mathrm{~T} 80$ & Con & $\mathrm{T} 20$ & T80 & Con & $\mathrm{T} 20$ & $\mathrm{~T} 80$ \\
\hline Kappa number decrease & 0.9 & 0.8 & 0.4 & 1.4 & 1.4 & 0.8 & 2.7 & 2.4 & 2 \\
\hline Brightness increase & 3.1 & 2.8 & 1.1 & 4.7 & 4.3 & 2 & 8.3 & 5.9 & 5 \\
\hline Viscosity decrease & 8 & 13 & -38 & 59 & 55 & -1 & 53 & 50 & 11 \\
\hline
\end{tabular}

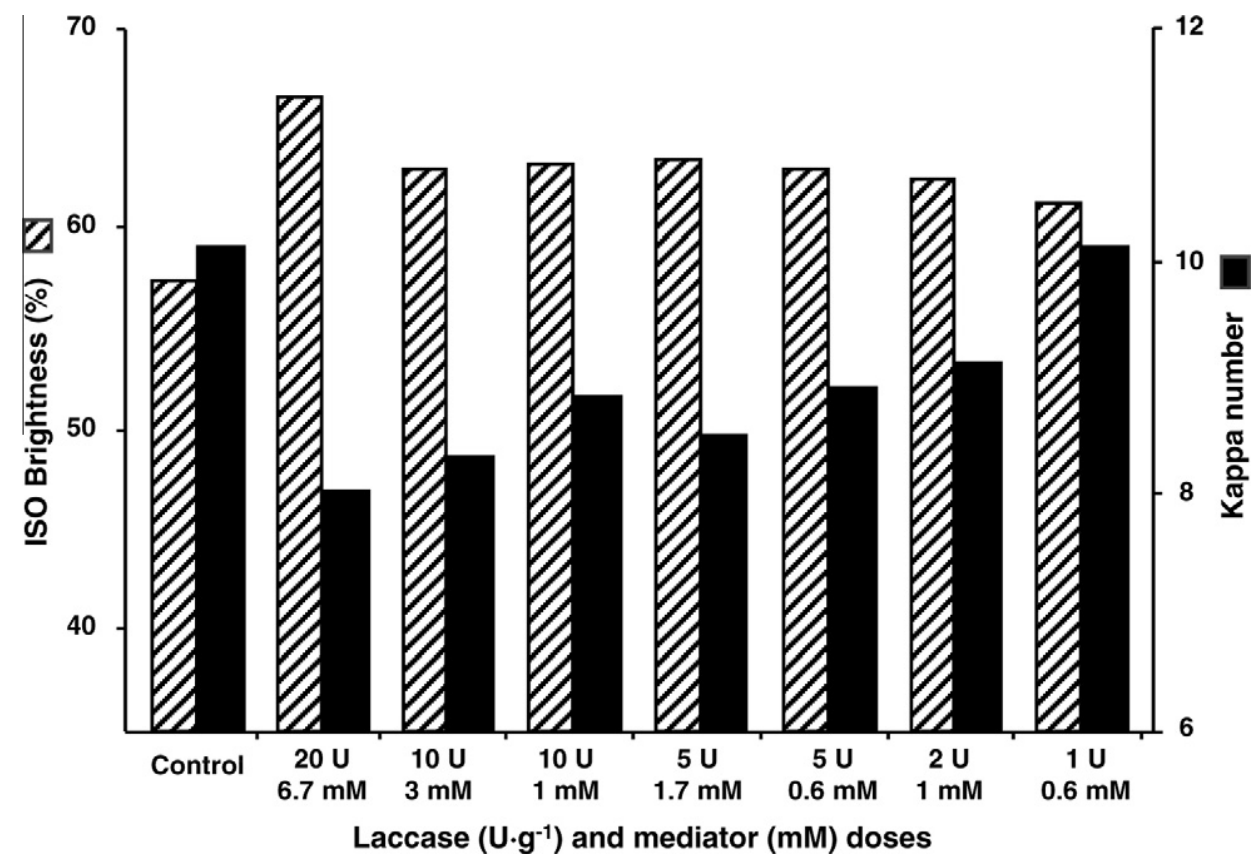

Fig. 1. Brightness and kappa number of eucalypt pulp after treatment with different doses of $M$. thermophila laccase (from $1 \mathrm{U} \mathrm{g}^{-1}$ to $20 \mathrm{U} \mathrm{g}^{-1}$ ) and methyl syringate (from $0.6 \mathrm{mM}$ to $6.7 \mathrm{mM}$ ) followed by an alkaline peroxide extraction, compared with control (without both laccase and mediator).

MtL alone (about $40 \%$ and $50 \%$ degradation, respectively) and in the presence of methyl syringate (about $50 \%$ and $45 \%$, respectively). No differences are observed between the addition of Tween 20 and Tween 80 revealing that only the surfactant effect seems to play a role in this removal.

\subsection{Laccase and mediator doses for pulp delignification and pitch} removal

Taking into account that the main obstacles that prevent the use of laccase-mediator systems in the pulp mill are the high costs arisen from the high doses of enzymes and mediators usually reported, therefore, lower enzyme and mediator (methyl syringate) doses have been evaluated here. Laccase dosages between $1 \mathrm{U} \mathrm{g}^{-1}$ and $20 \mathrm{U} \mathrm{g}^{-1}$ of pulp together with mediator doses from $0.6 \mathrm{mM}$ to $6.7 \mathrm{mM}$ were tested. Fig. 1 shows the brightness and kappa values (after the alkaline peroxide extraction) obtained using the different doses of laccase and mediator. It is noteworthy that no substantial differences were observed among the treatments using $10 \mathrm{U} \mathrm{g}^{-1}, 5 \mathrm{U} \mathrm{g}^{-1}$ or $2 \mathrm{U} \mathrm{g}^{-1}$ of laccase. Likewise, similar brightness results were obtained with methyl syringate doses from $0.6 \mathrm{mM}$ to $3 \mathrm{mM}$. The ability of methyl syringate to mediate the oxidation of non-phenolic lignin model compound at low mediator concentration levels has recently been reported (Nousiainen et al., 2009). Although the best brightness and kappa number results were obtained with the highest doses of laccase and mediator, promising results were observed with very low doses of laccase and mediator. Interestingly, when the pulp treatments were performed under oxygen pressure (Labomat experiments under conditions more similar to those of industrial application) the treatment duration could be reduced over $50 \%$ to attain similar kappa and brightness improvements, even with the lowest enzyme and mediator doses.

The removal of lipophilic extractives from these pulp samples was also evaluated (data not shown). Generally, no differences in the removal of the sterol esters and free sterols were observed among the different treatments and even better results in terms of sterol glycosides removal (54-74\% removal) were attained in treatments with low doses of enzyme $\left(1-2 \mathrm{U} \mathrm{g}^{-1}\right)$ and mediator (0.6-1.0 mM).

The combination of substantial bleaching benefits and effective control of pulp extractives giving less down-time may provide sufficient advantages for the enzymatic process to be a cost-effective alternative to current bleaching and extractive control programs.

\section{Conclusions}

In the work reported here, which includes the use of commercial MtL in the presence of lignin-derived phenolic mediators, an important increase of eucalypt pulp brightness and decrease of kappa number were attained using methyl syringate as mediator, together with high removal of pitch-forming lipophilic extractives. Moreover, by careful selection of the laccase-mediator couple, low enzyme-mediator doses are able to catalyze pulp delignification 
and lipid removal thus paving the way for an industrially-feasible cost-effective bleaching stage. This optimized enzymatic stage has potential for substituting oxygen delignification to achieve more sustainable TCF sequences, as suggested by pilot-scale trials currently in course.

\section{Acknowledgements}

This study was funded by the BIORENEW and LIGNODECO EU projects (NMP2-CT-2006-026456 and KBBE-2009-3-244362, respectively) and the ELLE and RAPERO Spanish MICINN (co-financed by FEDER funds) projects AGL2008-00709 and BIO200801533, respectively). Beldem (Andenne, Belgium) is acknowledged for the P. cinnabarinus laccase. S. Molina is acknowledged for preliminary laccase-mediator assays. E.D. Babot thanks the Spanish CSIC for a JAE fellowship.

\section{Appendix A. Supplementary data}

Supplementary data associated with this article can be found, in the online version, at doi:10.1016/j.biortech.2011.03.100.

\section{References}

Bajpai, P., Anand, A., Bajpai, P.K., 2006. Bleaching with lignin-oxidizing enzymes. Biotechnol. Annu. Rev. 12, 349-378.

Berka, R.M., Brown, S.H., Xu, F., Schneider, P., Oxenbøll, K.M., Asalyng, D.A., 1999 Purified Myceliophthora laccases and nucleic acids encoding same. Patent (USA) 5981243.

Berka, R.M., Schneider, P., Golightly, E.J., Brown, S.H., Madden, M., Brown, K.M. Halkier, T., Mondorf, K., Xu, F., 1997. Characterization of the gene encoding an extracellular laccase of Myceliophthora thermophila and analysis of the recombinant enzyme expressed in Aspergillus oryzae. Appl. Environ. Microbiol. 63, 3151-3157.

Bourbonnais, R., Paice, M.G., 1990. Oxidation of non-phenolic substrates. An expanded role for laccase in lignin biodegradation. FEBS Lett. 267, 99-102.

Bourbonnais, R., Paice, M.G., 1996. Enzymatic delignification of kraft pulp using laccase and a mediator. Tappi J. 79, 199-204.

Call, H.-P., 1994. Verfahren zur Veränderung, Abbau oder Bleichen von Lignin, ligninhaltigen Materialien oder ähnlichen Stoffen. Patent (International) WO $94 / 29510$.

Camarero, S., García, O., Vidal, T., Colom, J., del Río, J.C., Gutiérrez, A., Gras, J.M., Monje, R., Martínez, M.J., Martínez, A.T., 2004. Efficient bleaching of non-wood high-quality paper pulp using laccase-mediator system. Enzyme Microb. Technol. 35, 113-120.

Camarero, S., Ibarra, D., Martínez, A.T., Romero, J., Gutiérrez, A., del Río, J.C., 2007. Paper pulp delignification using laccase and natural mediators. Enzyme Microb. Technol. 40, 1264-1271.

del Río, J.C., Gutiérrez, A., Romero, J., Martínez, M.J., Martínez, A.T., 2001 Identification of residual lignin markers in eucalypt kraft pulps by Py-GC/MS J. Anal. Appl. Pyrolysis 58/59 425-433.

Fillat, A., Colom, J.F., Vidal, T., 2010. A new approach to the biobleaching of flax pulp with laccase using natural mediators. Bioresour. Technol. 101, 4104-4110.

Fillat, U., Roncero, M.B., 2010. Optimization of laccase-mediator system in producing biobleached flax pulp. Bioresour. Technol. 101, 181-187.

Gutiérrez, A., del Río, J.C., 2001. Gas chromatography-mass spectrometry demonstration of steryl glycosides in eucalypt wood, kraft pulp and process liquids. Rapid Commun. Mass Spectrom. 15, 2515-2520.

Gutiérrez, A., del Río, J.C., González-Vila, F.J., Martín, F., 1998. Analysis of lipophilic extractives from wood and pitch deposits by solid-phase extraction and gas chromatography. J. Chromatogr. 823, 449-455.

Gutiérrez, A., del Río, J.C., Ibarra, D., Rencoret, J., Romero, J., Speranza, M., Camarero, S., Martínez, M.J., Martínez, A.T., 2006a. Enzymatic removal of free and conjugated sterols forming pitch deposits in environmentally sound bleaching of eucalypt paper pulp. Environ. Sci. Technol. 40, 3416-3422.
Gutiérrez, A., del Río, J.C., Martínez, A.T., 2009. Microbial and enzymatic control of pitch in the pulp and paper industry. Appl. Microbiol. Biotechnol. 82, 10051018.

Gutiérrez, A., del Río, J.C., Martínez, M.J., Martínez, A.T., 2001a. The biotechnological control of pitch in paper pulp manufacturing. Trends Biotechnol. 19, 340-348.

Gutiérrez, A., del Río, J.C., Rencoret, J., Ibarra, D., Martínez, A.T., 2006b. Main lipophilic extractives in different paper pulp types can be removed using the laccase-mediator system. Appl. Microbiol. Biotechnol. 72, 845-851.

Gutiérrez, A., del Río, J.C., Rencoret, J., Ibarra, D., Speranza, A.M., Camarero, S. Martínez, M.J., Martínez, A.T., 2006c. Sistema enzima-mediador para el control de los depósitos de pitch en la fabricación de pasta y papel. Patent (International)ES2282020B1.

Gutiérrez, A., Rencoret, J., Ibarra, D., Molina, S., Camarero, S., Romero, J., del Río, J.C. Martínez, A.T., 2007. Removal of lipophilic extractives from paper pulp by laccase and lignin-derived phenols as natural mediators. Environ. Sci. Technol. $41,4124-4129$.

Gutiérrez, A., Romero, J., del Río, J.C., 2001b. Lipophilic extractives from Eucalyptus globulus pulp during kraft cooking followed by TCF and ECF bleaching. Holzforschung 55, 260-264.

Ibarra, D., Chávez, M.I., Rencoret, J., del Río, J.C., Gutiérrez, A., Romero, J., Camarero, S., Martínez, M.J., Jiménez-Barbero, J., Martínez, A.T., 2007. Lignin modification during Eucalyptus globulus kraft pulping followed by totally chlorine free bleaching: a two-dimensional nuclear magnetic resonance, Fourier transform infrared, and pyrolysis-gas chromatography/mass spectrometry study. J. Agric. Food Chem. 55, 3477-3499.

Ibarra, D., Romero, J., Martínez, M.J., Martínez, A.T., Camarero, S., 2006. Exploring the enzymatic parameters for optimal delignification of eucalypt pulp by laccasemediator. Enzyme Microb. Technol. 39, 1319-1327.

International Organization for Standardization Documentation and Information (ISO), 2003. ISO Standards Collection on CD-ROM. Paper, board and pulps. ISO Geneva.

Jensen, K.A.Jr., Bao, W., Kawai, S., Srebotnik, E., Hammel, K.E., 1996. Manganesedependent cleavage of non-phenolic lignin structures by Ceriporiopsis subvermispora in the absence of lignin peroxidase. Appl. Environ. Microbiol. $62,3679-3686$.

Johnsson, L., 2004. Phytosterol oxidation products; Formation, analysis and occurrence. Doctoral thesis, Swedish University of Agricultural Sciences, Uppsala.

Kenealy, W.R., Jeffries, T.W., 2003. Enzyme processes for pulp and paper: a review of recent developments. In: Coodell, B. Nicholas, D.D. Schultz, T.P. (Eds.) Wood Deterioration and Preservation: Advances in Our Changing World. American Chemical Society, San Diego, pp. 210-239.

Kulys, J., Krikstopaitis, K., Ziemys, A., Schneider, P., 2002. Laccase-catalyzed oxidation of syringates in presence of albumins. J. Mol. Catal. B Enzym. 18, $99-108$

Mayer, A.M., Staples, R.C., 2002. Laccase: new functions for an old enzyme Phytochemistry 60, 551-565.

Moldes, D., Vidal, T., 2008. Laccase-HBT bleaching of eucalyptus kraft pulp: Influence of the operating conditions. Bioresour. Technol. 99, 8565-8570.

Molina, S., Rencoret, J., del Río, J.C., Lomascolo, A., Record, E., Martínez, A.T. Gutiérrez, A., 2008. Oxidative degradation of model lipids representative for main paper pulp lipophilic extractives by the laccase-mediator system. Appl. Microbiol. Biotechnol. 80, 211-222.

Nousiainen, P., Maijala, P., Hatakka, A., Martínez, A.T., Sipila, J., 2009. Syringyl-type simple plant phenolics as mediating oxidants in laccase catalyzed degradation of lignocellulosic materials: model compound studies. Holzforschung 63, 699704.

Poppius-Levlin, K., Wang, W., Tamminen, T., Hortling, B., Viikari, L., Niku-Paavola, M.-L., 1999. Effects of laccase/HBT treatment on pulp and lignin structures. J. Pulp Paper Sci. 25, 90-94.

Valls, C., Molina, S., Vidal, T., del Río, J.C., Colom, J., Martínez, A.T., Gutiérrez, A. Roncero, M.B., 2009. Influence of operation conditions on laccase-mediator removal of sterols from eucalypt pulp. Process Biochem. 44, 1032-1038.

Xu, F., Shin, W.S., Brown, S.H., Wahleithner, J.A., Sundaram, U.M., Solomon, E.I., 1996. A study of a series of recombinant fungal laccases and bilirubin oxidase that exhibit significant differences in redox potential, substrate specificity, and stability BBA. Protein Struct. Mol. Enzym. 1292, 303-311.

Zhang, X., Renaud, S., Paice, M., 2005. The potential of laccase to remove extractives present in pulp and white water from TMP newsprint mills. J. Pulp Paper Sci. 31, 175-180. 
Supplementary data 1. Fig. S1. Single-ion chromatographic traces of markers from Py-GC/MS of paper pulp (control, before alkaline peroxide extraction) used to estimate the lignin S/G ratio. G-lignin markers (A) included: 4-Methylguaiacol ( $\mathrm{m} / \mathrm{z} 138)$, 4-ethylguaiacol $(\mathrm{m} / \mathrm{z} 152)$, 4-vinylguaiacol $(\mathrm{m} / \mathrm{z} 150)$ and 4-tpropenylguaiacol $(\mathrm{m} / \mathrm{z} 164)$. S-lignin markers (B) included: 4-Methylsyringol $(\mathrm{m} / \mathrm{z} 168)$, 4-ethylsyringol $(\mathrm{m} / \mathrm{z}$ $182)$, 4-vinylsyringol ( $m / z 180)$ and 4-t-propenylsyringol ( $m / z 194)$. Same vertical scale was used in $A$ and B chromatographic traces. Fig. S2. GC-MS analysis (total-ion chromatograms) and chemical structures of the main lipophilic compounds identified in eucalypt kraft pulp (without alkaline peroxide extraction) before (A) and after treatment with laccase $M$. thermophila using syringaldehyde $(B)$ and methyl syringate $(C)$ as mediators. Peak identification: (a) stigmasta-3,5,7-triene; (b) stigmasta-3,5-diene; (c) sitosterol; (d) 7-

hydroxysitosterol; (e) sitostanetriol; (f) 7-ketositosterol; (g) sitosteryl 3ß-d-glucopyranoside; (h) sitosteryl 9oxononanoate; (i) 7-ketositosteryl 3 $\beta$-d-glucopyranoside; and (j) sitosterol esters. Same vertical scale was used in the three chromatograms. 

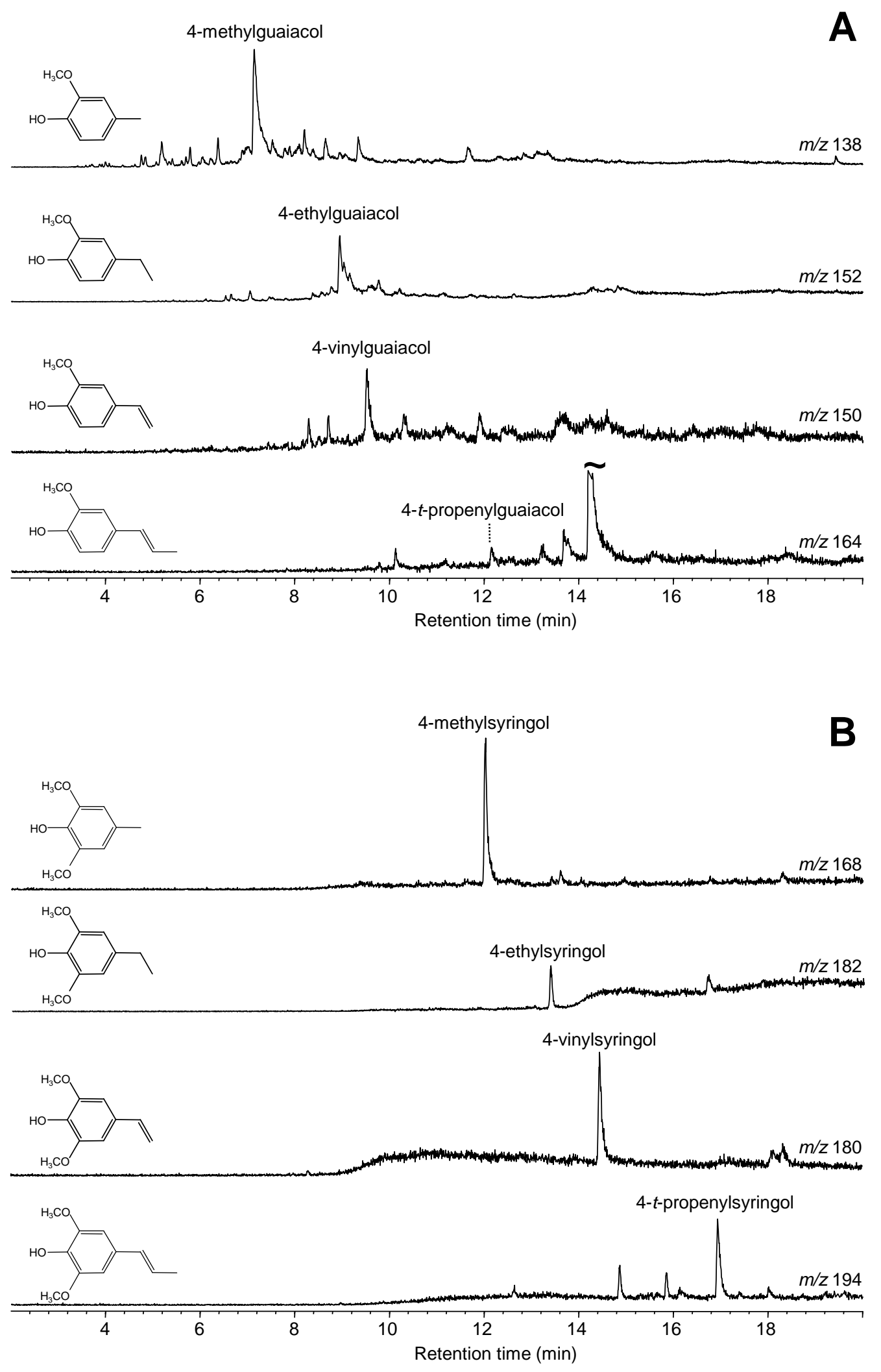

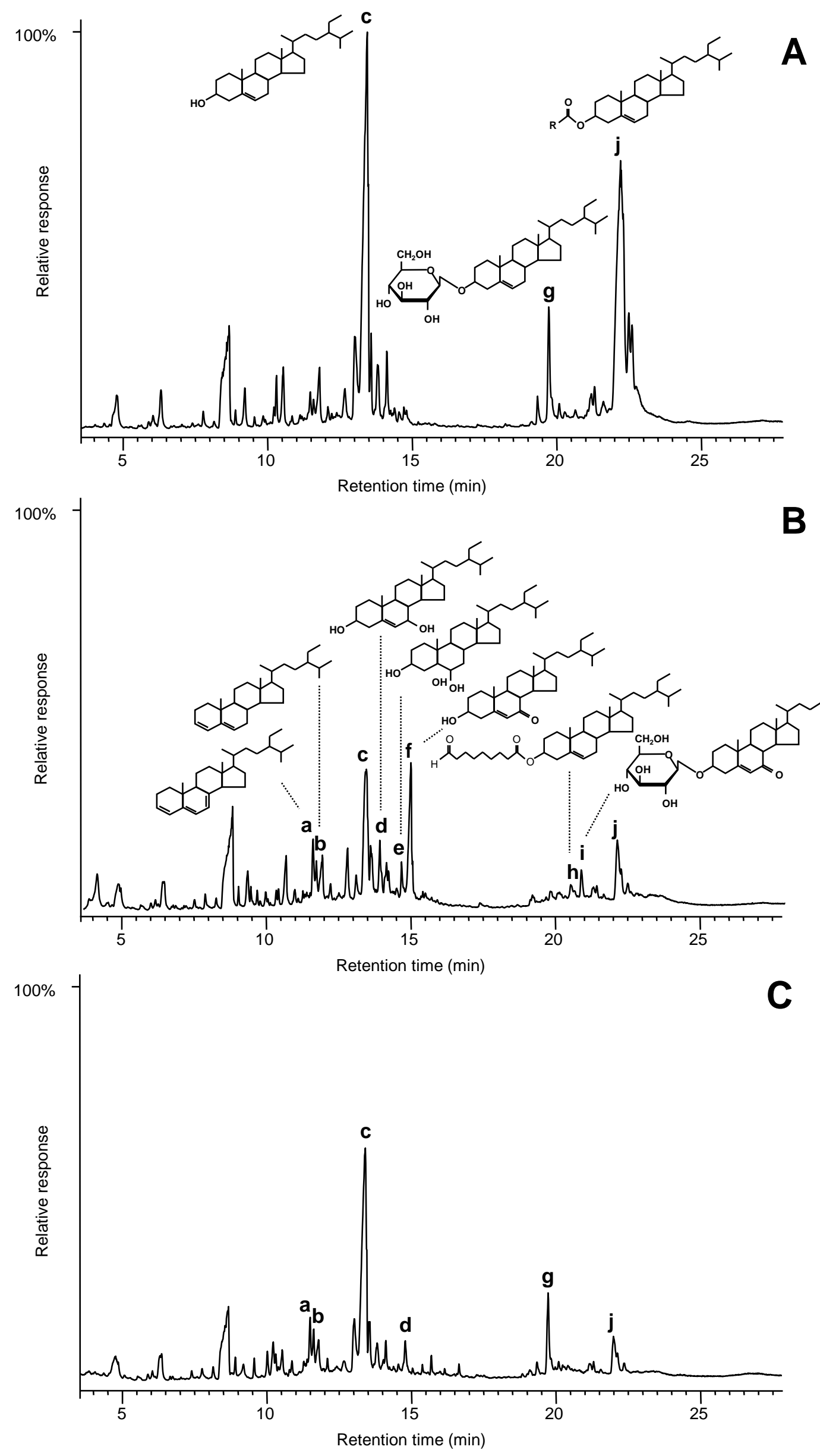

Figure S2 